\title{
Encoding Contrast, Inviting Disapproval: The Place of Ata in Belizean Kriol
}

\author{
WILLIAM SALMON \\ University of Minnesota, Duluth ${ }^{1}$
}

\section{$1 \quad$ Introduction}

This paper investigates the semantics and pragmatics of the discourse marker ata in Belizean Kriol, as seen in (1). I show that ata is an adversative discourse marker similar to the Spanish discourse marker $s i$, as described in Schwenter $(1999,2002)$, and that the two share much in terms of syntax, semantics, and pragmatics. This is interesting, as there seems to be no English counterpart to the Kriol ata or Spanish si.
A: Wai yu nak yu sista? ${ }^{2}$
B: $\quad$ Ata da shee nak me fos! [KID]
A: Why did you hit your sister?
B: $\quad$ (But) it was she who hit me first! ${ }^{3}$

In terms of ata, I argue that it is used to convey an emphatic contrast with the immediately preceding discourse and that this contrast is a conventional implicature of the type described in Grice (1975). In addition, it is frequently used in conveying negative attitudes toward the preceding discourse. I argue that this is not a conventional aspect of ata's meaning but that it is instead calculated in context via Gricean pragmatic reasoning as a conversational implicature. Finally, I suggest a diachronic origin for $a t a$ in the Kriol focus marker $d a$. This present account of ata, then, covers significantly different ground than the account given in Salmon (to appear). In the next section, which follows from Salmon (to appear), I provide a brief background on the Kriol language as well as a discussion of where and how the data used in this paper were collected.

\subsection{On Belizean Kriol}

\footnotetext{
${ }^{1}$ Many thanks to the audience at the University of Minnesota Institute of Linguistics where this paper was presented in January 2014. Thanks also to Eve Sweetser, Martina Faller, and Michael Ellsworth for very helpful comments in the question and answer session of the BLS presentation.

${ }^{2}$ The spelling system used in this paper was proposed for Kriol by members of the Belize Kriol Project in 2002 . The orthography is completely phonetic, with each symbol representing only one sound. See Decker (2005) for discussion and history. Sometimes it is necessary to provide interlinear glosses for the Kriol examples, and in these cases I have done so. When the translation to Standard English is straightforward, though, I omit the glosses in the interest of brevity.

${ }^{3}$ Following Schwenter (1999) and the dilemma for glossing adversative discourse marker si in Spanish, which similarly has no direct English counterpart, I will leave ata unglossed in later examples.
} 
Belizean Kriol is an English-based creole spoken in the Central American/Caribbean country of Belize. It is sometimes considered to be the language specific to the Creole people there-those of Afro-European descent - but this is not correct, as many Belizeans speak Kriol and do not consider themselves to be Creole, and the language has become something of an unofficial lingua franca across the country. ${ }^{4}$ Though the official language is English, most Belizeans of all races and ethnicities can speak Kriol with differing degrees of proficiency. There is also a strong movement underway by the Belize Kriol Project and National Kriol Council of Belize to promote the language and culture in the country. ${ }^{5}$ To this end, there is a dictionary of Kriol (Kriol-Inglish Dikshineri) which defines many Kriol words and gives a brief grammatical description. There have also been more in-depth descriptions of the grammar, in Young (1973), Greene (1999), and Decker (2005). There is also a limited literary tradition written in Kriol as well as a weekly newspaper column in The Reporter, of Belize City.

\subsection{Research Methods}

I consulted 20 speakers of Belizean Kriol, with half of the speakers residing in Belize City and half from Punta Gorda. The paper was a work in progress while I was in Belize, so the information I gathered from early consultants helped me to sharpen my questions to those I interviewed later. As such, I did not receive 20 grammaticality judgments on each piece of data. However, I did make sure to test each piece of data with several speakers, gathering at least 5-10 judgments for each piece of data, and as many as 15 for others.

The consultants were of both sexes, and various ages, with the youngest being 18 and the oldest consultants being three women between the ages of 70-80. I also consulted several men in their 30s and 40s. Some of the speakers were bilingual with English and Kriol, and some reported speaking only Kriol.

The data I use in this paper are of several kinds: There is directly elicited data concerning specific questions about the lexical items bot and ata, as well as recordings of conversation and unplanned discourse that I made in Belize City and Punta Gorda in January 2013. I have also made use of the Kriol-Inglish Dikshineri, which is published in cooperation with the Belize Kriol Project and Belize's Ministry of Education. Examples taken from this work are tagged throughout the paper as "KID". In addition, I have modified several example sentences from KID from unrelated dictionary entries as a means of testing acceptability intuitions among speakers of Kriol.

\section{Bot and Ata: Empirical Descriptions}

\footnotetext{
${ }^{4}$ See Escure (1997: 28-39) for a sociohistorical outline of Belizean Kriol, and suggestions as to the putative origins of Kriol in contact between Africans, Europeans, and Miskito Indians in the 18th and 19th centuries.

${ }^{5}$ Much of the work of these two organizations can be seen at the following web site: <http://www.kriol.org.bz/>.
} 
There has been little prior work on ata in the linguistics literature, with the exception of Salmon (to appear), which is the source of much of the empirical coverage provided in the present paper. We begin with a brief empirical look at bot, which is very close to English but, and which is the closest thing possible to an English translation of ata.

\section{$2.1 \quad$ Bot}

Bot, which is pronounced [bot], or sometimes [bot], is very similar to English 'but' in many of its syntactic and semantic properties. Like but, bot is polyfunctional, though the two are not identical, as I will show below.

Consider (2), with bot in initial position of the second clause in each sentence. In both examples, bot translates transparently to English as standard usages of but. Essentially, bot/but here conjoins two clauses and conveys that the second clause is somehow in contrast with the first clause.

(2) Hihn da-mi wahn shaat man, bot ih $\mathrm{mi}$ fat ahn schrang tu. he was a short man but he PAST fat and strong too

'He was a short man, but he was fat and strong, too'. [KID]

In addition to the conjunctive examples, we also find the exceptive, prepositional use of bot, which compares to the common usage and syntactic configuration of English but. The Kriol sentence in (3) is perfectly acceptable, as is its English translation.

(3) Mi ma mi wap all a wi bot mi lee breda.

my mother PST punish all of us but my little brother

'My mother punished all of us but my little brother'. [KID]

The corrective use of bot in (4) was also accepted by my Kriol consultants in the given context.

(4) [Context: You ordered juice, and the waiter brought you Coca Cola by mistake.] Ah noh waahn Coke, bot joos.

I don't want Coke, but juice'.

Another similarity shared between but and bot is that both are awkward to contemporary speakers in adverbial uses. For example, in (5a) we see the adverbial use of bot to mean 'only'. My consultants rejected this as extremely awkward, and suggested correcting it with oanli 'only' as in (5b).

(5) a. \#Georgiana da-mi bot ten yaaz oal.

'Georgiana was but ten years old'. 
b. Georgiana da-mi oanli ten yaaz oal.

This is not surprising, however, as this is an archaic, idiomatic usage of but, which sounds awkward to the native American English speakers that I polled as well, and Biber et al. (1999: 81) note that this adverbial use of but is heavily restricted by context.

More interesting for the purposes of this paper is the appearance of bot in sentence- and utterance-initial position, in which it relates the bot-sentence to some aspect of the preceding discourse. Consider (6), in which the speakers are reminiscing about their old neighborhood [from Greene (1999: 211)]. Here we see speaker B using bot to mark a contrast with something implied by speaker A's statement. That is, speaker A describes how they used to be punished as children, and speaker B intends her statement to contrast with an inference of this: namely, that if one is punished then one will cease to get into trouble.

(6) A: Breda Luke yoostu liv deh tu bikaaz wen ih yoostu get chrobl dehn yoostu put dehn finga pahn greta.

B: $\quad$ Bot dehn stil get chroble, speshali Pati.

A: Brother Luke used to live there too, because when he used to get in trouble, they used to smack their hands with a ruler.

B: But they still got into trouble, especially Patty.

This sentence-initial, discourse marking bot in (6) compares directly to what we will see below with $a t a$, which is required to be sentence-initial. Ata differs, though, in that it has a more specialized semantics than bot and that it occurs only in casual speech. Let's take a closer look at ata now.

\subsection{Ata}

My Kriol consultants generally pronounce ata as ['ata], with primary stress on the initial syllable, and without aspiration on the medial but syllable-initial [t]. The initial vowel often seems to be lengthened as well, and there is generally no pause separating the discourse marker from the sentence that hosts it. In general, ata seems to be found only in spoken, unplanned speech (Ochs, 1979). It is common to find examples of sentence-initial, discourse marking bot in written form, but I have been unable to find ata outside of casual speech. Several of my consultants remarked that they would only use ata in informal situations; otherwise, they would feel more comfortable using bot.

The Kriol-Inglish Dikshineri (2007: 31) has a single entry for ata, which is given in full below in (7).

(7) ata conj. but. (Generally denotes bad attitude.) 
As I will show below, ata is much more restricted syntactically and pragmatically than bot is. Bot can replace ata in all cases, but ata cannot replace bot in all cases. Also, I will show that use of ata doesn't necessarily require a bad attitude, as the entry quoted in (7) suggests. Rather, speakers use it to mark an emphatic contradiction with the immediately preceding discourse. As a result, it is not surprising that ata would seem to denote a bad attitude, as in moments of emphatic contrast speakers are often negative or confrontational. I will argue below, however, that this emotive message is not conventionally encoded but is instead derived pragmatically, resulting in a relatively minimal semantics for $a t a$.

Another important fact about ata is that it appears only in sentence-initial syntactic position. In my conversations and recorded data with consultants, all of the tokens of ata that I have are in sentence-initial position, used in an immediate response to a previous speaker. For example, consider (1) again from above, in which ata is sentence-initial in B's response to A, and in which ata is used to contradict a contextual inference generated by A's question: B takes A to imply that she is somehow unjustified in hitting her sister.

(1) A: Wai yu nak yu sista?

B: $\quad$ Ata da shee nak me fos!

A: Why did you hit your sister?

B: $\quad$ ATA it was she who hit me first!

Similarly, in (8), which is part of my recorded data, ata appears in initial position. Here, two men were talking about their plans to have met on the previous day at a gas station in Punta Gorda. There was some miscommunication, however, and the two failed to connect.
A: $\quad$ Yu da rong gyas stayshan!
B: $\quad$ Ata no da-mi rong stayshan yesideh!
A: $\quad$ You (were) at the wrong gas station!
B: $\quad$ ATA (I) was not (at) the wrong station yesterday!

A similar use occurred later in this same conversation, when another man walked up and joined the men already there. One man asked the newcomer what he had done on the previous day. The newcomer responded that he was at home, but this didn't match with what the first speaker believed, so he objected to the newcomer's claim, using ata, and so marking a contrast with the newcomer's assertion and with what he had believed about the newcomer previously.

(9) A: Wat yu deh gwaahn yestudeh, mayn?

B: $\quad$ Yestudeh da-mi hoahn. 
A: $\quad$ Ata ai si yu yestudeh! Ai si yu yestudeh bai Braddick! Rait?

A: What did you do yesterday, man?

B: $\quad$ Yesterday I was at home.

A: $\quad$ ATA I saw you yesterday! I saw you yesterday by Braddick’s! Right?

The tokens in (8) and (9) were taken from recorded, unplanned speech, and are sentence-initial. In addition to this recorded data, I also tested my consultants directly with respect to the possibility of ata in sentence-internal positions that I constructed. To do so, I took grammatical bot-sentences from KID, and replaced bot with ata, as in (10) and (11).

(10) \#Hihn da-mi wahn shaat man, ata ih mi fat ahn schrang tu. he was a short man but he PAST fat and strong too 'He was a short man, ATA he was fat and strong, too'. [KID]

(11) \#Yu di play bembeh ata Ah noh frayd fi yoo you PRES.PROG pretend tough but I not afraid of you.EMPH 'You're pretending to be tough, ATA I'm not afraid of you'. [KID]

For each of these sentences, I asked my Punta Gorda consultants if the sentence would be acceptable. The response was negative.

I also tested adapted sentences using ata in place of exceptive and corrective bot, as in (12) and (13), and these were judged to be unacceptable.

(12) \#Mi ma mi wap all a wi ata mi lee breda. my mother PST punish all of us but my little brother 'My mother punished all of us ATA my little brother'.

(13) [Context: You ordered juice, and the waiter brought you Coca Cola by mistake.] \#Ah noh waahn Coke, ata joos. I don't want Coke, ATA juice'.

Similarly, I tested ata in a sentence where it should mean 'only', akin to (5) above. This was also found to be unacceptable, as in (14).

(14) a. \#Georgiana da-mi ata ten yaaz oal.

'Georgiana was ATA ten years old'.

b. Georgiana da-mi oanli ten yaaz oal. 
In all of the sentences tested above, ata falls in sentence-internal position and is found to be unacceptable.

I also tested ata in clause-initial position, but immediately following a vocative address, as in (15). This too was not accepted. ${ }^{6}$

(15) A: Ai mi tink yoo bai di groasriz!

B: $\quad$ \#Luis, ata Ai bai di rom!

A: I thought you bought the groceries!

B: Luis, ATA I bought the rum!

It seems clear that ata strongly resists appearing in sentence-internal positions - even if those positions are clause-initial within the sentence. In this way, ata differs significantly from bot. Ata also differs from bot in that its semantics encode an emphatic contrast to the immediately preceding discourse and that it must appear in a dialogic or multi-speaker situation. Bot encodes contrast, but it clearly lacks the additional requirements of ata, as bot can be perfectly felicitous in sentence-internal, monologual speech. Thus, part of what ata encodes conventionally is information about the kinds of contexts in which it appears.

A very clear comparison here can be seen with the constructions Fillmore, Kay, and O’Connor (1988: 506) argue to have "pragmatic point". Fillmore et al. describe pragmatic point as follows:

We find that in many cases idiomatic expressions have special pragmatic purposes associated with them. A large number of substantive idioms have obvious associated pragmatic practices (e.g. Good morning, How do you do?, once upon a time) $[\ldots]$... Him be a doctor?

The final construction mentioned here by Fillmore et al. is referred to as a Mad Magazine Sentence (MMS) in Akmajian (1984) and Lambrecht (1990, 1994). Like ata, it encodes information about the kind of pragmatic situation in which it must occur. The MMS must be uttered as a response to a dubious assertion or presupposition, and it generally requires a rising intonation. In other words, a second speaker has to have said something about "him" becoming a doctor, and this proposition has to be considered dubious or unlikely by the person who responds, as in (16B).

(16) A: I think John will be a great doctor someday.

B: Him be a doctor?!

\footnotetext{
${ }^{6}$ This exchange was accepted only when there was a lengthy pause inserted between Luis and ata. This has the effect though of fully separating the vocative and ata, resulting in a sentence in which ata is still sentence-initial.
} 
B cannot simply use the construction out of the blue - she must be responding to the speech of a second person. This situational dependency and specific pragmatic purpose are what Fillmore et al. are concerned with when they discuss a construction as having pragmatic point, and this is very similar to what we see with $a t a$, which must be used to respond to and contradict some aspect of the immediately preceding discourse. Like the MMS, ata has a Hey, wait a minute! feel to it. Both constructions are dialogic and must appear in a dialogue or multiparty exchange. This is also consistent with Fraser's (2006: 197) description of various other discourse markers that require at least two speakers for felicitous use. Consider (17), which is Fraser's (26a), and in which use of on the contrary as a DM seems to require at least two speakers, with speaker B responding to speaker A.

(17) a. Fred is a nice guy. *On the contrary, he is a boor.

b. A: Fred is a nice guy.

B: On the contrary, he is a boor.

We can see then that on the contrary, the MMS, and ata are strongly interactional in that they are all used to respond to context and at the same time to create context. I am claiming especially for ata that this translates to a licensing requirement that is conventionally associated with the word itself.

\subsection{The Meaning of Ata}

As we have seen thus far, ata marks an emphatic contrast with some aspect of preceding discourse. I will argue that this content is conventional, semantic meaning, but that it is non-truth conditional meaning, and as such, that this contrast meaning should be analyzed as a Gricean (1975) conventional implicature in much the same way that the contrastive element of but is often described. $^{7}$

There have been many, many accounts given over the years of the meaning of but, which differ in everything from theoretical framework to empirical claims about what but means in the first place. As such, I cannot review all of them here. ${ }^{8}$ For the purposes of this essay, I am

\footnotetext{
${ }^{7}$ In this paper I am concerned only with Grice's original conception of conventional implicature. Since Grice's description of this class of meaning, it has been given at least two reinterpretations, for example, in Karttunen and Peters (1979), and more recently in Potts (2005). These reinterpretations fundamentally alter Grice's category, and generally make different empirical predictions than does Grice's original description. For example, Potts (2005) does not consider Grice's data such as but as a conventional implicature device at all. See Salmon (2011) and Horn (2013) for arguments against Potts's (2005) system and in favor of Grice's original arrangement of the category, especially for the kinds of data with which Grice was originally concerned.

${ }^{8}$ See, for instance, Biber et al. (1999), Huddleston and Pullum (2003), Hall (2004), and the many sources therein. Toosarvandani (to appear) provides a very clear and recent discussion of the semantics of the counterexpectational, corrective and opposition uses of but as well as a landscape of prior semantic and pragmatic accounts of the conjunction.
} 
assuming a roughly Gricean understanding of but, which is common in the semantics and pragmatics literature. ${ }^{9}$

Grice (1975: 25-26) argued that but shares the same truth conditions as and, which is essentially that of logical conjunction. In addition, but also conveys a conventional implicature (CI) of contrast, which is conventional, semantic meaning, but which does not affect the truth conditions of a proposition containing but. ${ }^{10}$ Essentially, (18a) has the same truth conditions as (18b) and (18c). However, (18a) and (18b) differ in that (18a) conveys the CI given in (18d) in addition to the logical conjunction of (18c). The meaning in (18d) is conventional, semantic meaning, but it does not affect the truth conditions of (18a).
a. He is poor, but he is honest.
b. He is poor, and he is honest.
c. [he is poor] \& [he is honest]
d. CI: There is some contrast between being poor and honest.

Thus, but has a multidimensional semantic meaning, with one dimension being truth conditional and the other being a non-truth conditional statement of contrast.

The contrastive component of ata's meaning is similar. Ata is used to signal a contrast with some aspect of preceding discourse, but it does not change the truth conditions of its host sentence. Thus the contrast is part of ata's semantic, lexical meaning, but it is non-truth conditional. This was tested with a written questionnaire with my Belizean consultants, described below in discussion of examples (19)-(20).

I addressed the question of ata's truth conditions by arranging sets of test sentences such as (19a-c) below, which consist of an ata sentence, its bot counterpart, and then a third sentence with no discourse marker. I included all three sentences on a sheet of paper, and then asked my consultants if they could think of a scenario in which (19a) would be true, but (19b) or (19c) would be false.
a. $\quad$ Ata da shee nak me fos!
b. Bot da shee nak me fos!
c. Da shee nak me fos!

\footnotetext{
${ }^{9}$ See reference works in the Gricean tradition such as Levinson (1983: 128), Horn (2004: 4) and Huang (2007: 54) for verification of this. There are dissenters, though, such as Bach (1999), who is strongly Gricean, but who believes that conventional implicatures do not exist and are an unnecessary complication of Grice's framework. Similarly, in the semantic-pragmatic framework of relevance theory, conventional implicature, as Carston (2004: 633) writes, "simply does not arise". In relevance theory, conventional implicature devices are generally analyzed as "encoding procedural constraints on the inferential processes involved in deriving conversational implicatures". See also Blakemore (2002: 45-48) and Carston (2002: 108) for discussion of conventional implicature meaning from the perspective of relevance theory.

${ }^{10}$ See Levinson (1983: 128), Horn (2004: 4) and Huang (2007: 54) for succinct definitions of conventional implicature. Also, Horn (2013) provides an extended history of the concept, tracing it at least to Frege's Der Gedanke 'The Thought' (1918).
} 
'(But) it was she who hit me first!'

My consultants agreed that there was no difference in the kind of event described. All three of the sentences make a claim about who hit whom first. The ata sentence in (19a) was also commonly described as being more likely to occur in an argument, or in a situation in which the speaker feels as if she is being blamed unfairly, etc.

Another set of sentences I used is seen in (20a-c).
a. Ata yu neva tel mi tek owt di chrash.
b. Bot yu neva tel mi tek owt di chrash.
c. Yu neva tel mi tek owt di chrash.

(But) you never told me to take out the trash'.

My consultants agreed here too that the sentences in (21a-c) could all be used to describe the same event, similar to what we saw in (19). The ata-sentence here seemed to express surprise, as if someone had unfairly chastised the speaker for not taking out the trash.

Example (21) works in a similar fashion. Speaker A accuses B of stealing something, and $B$ retorts in anger and surprise in (21a) that it was actually speaker A who has stolen it.
A: Wai yu teef dat?
B: a. Ata yoo du it! ${ }^{11}$
b. Bot yoo du it!
c. Yoo du it!

A: Why did you steal that?

B: (But) you did it!

The central claims of these sentences do not change with the change in discourse marker, and this is a strong argument that ata does not make a truth conditional contribution.

What ata does do, I am arguing, is signal an emphatic contrast with the preceding discourse, which is analyzable as a Gricean conventional implicature. Since the emphatic contrast is a conventional part of ata's meaning, it should not be cancelable or defeated in contexts in which it is not supported. We can find evidence that this is so quite straightforwardly. Consider (22), in which a waitress brings a bottle of water for a customer. With the waitress' sentence, she implies that the water is all that the customer will be drinking. The customer isn't sure if he wants more than just water or not: he might want coffee too, but he isn't sure yet. So, he can use bot to indicate a mild contrast with the conversational implicature conveyed by the

\footnotetext{
${ }^{11}$ Kriol has emphatic forms for many of the personal pronouns, which differ from the unmarked default forms. For example, all of the left-side forms are reserved for emphatic use: yoo/yu 'you', $A i / A h$ 'I', shee/ih 'she', mee/mi 'me', etc. These emphatic pronouns seem likely candidates for Gricean conventional implicature analyses as well.
} 
waitress. However, in this neutral, non-emphatic context, it is very odd for him to respond to the waitress with ata.

[Ordering in a restaurant.]

Waiter: $\quad$ Yu aada waata, rait?

[Customer thinks about it for a second, and then speaks slowly.]

Customer: $\quad$ \#Ata/bot $\}$ maybi Ah waahn kaafi tu.

Waiter: $\quad$ You ordered water, right?

Customer: But maybe I want coffee too.

We see, then, that the context needs to support an emphatic contrast in order to license the use of ata. If it does not, then ata is infelicitous. This is consistent with my claim that ata encodes emphatic contrast. On the other hand, if emphatic contrast were not conventionally encoded, we would expect it to be rejected in contexts such as (22) which do not support it.

What about the emotive "bad attitude" of ata as described in the dictionary entry above in (7)? We saw in the survey examples of (19)-(21) that ata does not alter the truth conditions of the sentence which hosts it. There, we were interested only in the contrastive component of ata; however, it follows from those examples that the emotive element-however we define it - does not affect truth conditions either. In terms of semantics and pragmatics, this means that we would need to analyze the emotive component of ata as either a conventional implicature or a pragmatically derived conversational implicature, depending on whether or not the emotive component can be shown to be a conventional, semantic aspect of ata's meaning.

A quick way to show that the bad attitude is not part of ata's meaning is to find an example in which the bad attitude is missing. I asked consultants directly if it was necessary to be angry or have a bad attitude in the use of ata, and they said that it was not necessary. They said that it is common to use it in arguments, but that it wasn't necessary to be upset or angry, and that it can be used any time the speaker is excited. Some consultants also mentioned that they would use it when they were excited in informal situations. So, based on my consultants' intuitions, it seems that use of ata does not require a bad attitude.

Consider (9) again. I was present when this exchange occurred, and there was no suggestion of anger or bad attitude on the part of either speaker. Instead, speaker A was merely surprised at the information given by speaker B, which didn't match what A had previously believed. The conversation continued after this to a mundane, non-emotive topic.

(9) A: Wat yu deh gwaahn yestudeh, mayn?

B: Yestudeh da-mi hoahn.

A: Ata ai si yu yestudeh! Ai si yu yestudeh bai Braddick! Rait? 
A: What did you do yesterday, man?

B: Yesterday I was at home.

A: ATA I saw you yesterday! I saw you yesterday by Braddick’s! Right?

The absence of emotion or bad attitude in this exchange suggests that this is not a conventional component of ata's meaning, and this matches precisely with my consultants' own intuitions about how ata can be used.

Accordingly, if the emotive component is not conventionally associated with ata, then it cannot be a conventional implicature, as this category of meaning is by definition noncancelable. ${ }^{12}$ The only remaining option is that it must be pragmatically derived in context or conveyed via paralinguistic signals above and beyond the linguistic content. The latter optionparalinguistic signals such as body language, tone, etc. - are certainly significant, but they are beyond the scope of this paper. In addition to these, however, I believe that a kind of Gricean reasoning plays a role in the process above and beyond any paralinguistic signal. That is, if a speaker chooses to use the more restricted ata rather than a less restrictive alternative, such as bot, she then invites inferences that there is something marked about the situation, which could very well be interpreted as the speaker being upset or, in the words of KID, having "a bad attitude".

We can look to Horn's $(1984,2004)$ Division of Pragmatic Labor as a means of understanding this inference process. ${ }^{13}$ Here is Horn (1984: 22) in a description of the process:

The use of a marked (relatively complex and/or prolix) expression when a corresponding unmarked (simpler, less 'effortful') alternate expression is available tends to be interpreted as conveying a marked message (one which the unmarked alternative would not or could not have conveyed). Essentially, if a marked expression is used to describe a situation, it is likely that the speaker believes there is something marked or unusual about the situation itself. This invites addressees to infer or calculate conversational implicatures above and beyond the literal message. Horn (2004: 16) illustrates this process, as in (23):
a. He stopped the machine.
b. He got the machine to stop.
c. There is something unusual about the way he got the machine to stop.

While (23a-b) seem to be truth-conditionally consistent, (23b), which is more marked and prolix, conveys a conversational implicature that there is something unusual in the way he got the machine to stop, as in (23c).

\footnotetext{
${ }^{12}$ Horn (2004: 2) provides a succinct characterization of the Gricean conventional implicature: "Such detachable but non-cancelable aspects of meaning that are neither part of what is said nor calculable from what is said are conventional implicatures".

${ }^{13}$ See McCawley (1978) for description of a similar reasoning process. See Levinson (1983: 117) and Grice (1989: $31)$ on the role of calculability in conversational implicatures in general.
} 
Horn is concerned here primarily with markedness as a product of prolixity. However, markedness can be achieved many ways. ${ }^{14}$ We have seen thus far that ata is much more restricted syntactically, semantically, and pragmatically, than bot is. Thus, by its very nature it is a much more marked term, and as we have seen above, bot can appear in any of the ata examples, but the reverse is not true. Accordingly, a speaker's use of the marked ata can invite the addressee to draw inferences with respect to a marked situation, including the speaker's intention or state of mind in using the term. If the term encodes emphatic contrast, as I am arguing, it is only a small step from there to inferring an angry or negative state of mind on the part of the speaker. However, as I have shown above with respect to (9), this negative emotional message is not present in every use of the term. It is cancelable, and so it is non-conventional. The emotive content can thus be excluded from the lexical semantic content of ata, resulting in a simpler, more minimal semantics for the word.

In the next section, I provide a brief comparison of ata with the Spanish adversative discourse marker si, as described in Schwenter (1998, 2002), which is seen to be very similar to ata in its syntax, semantics, and pragmatics.

\section{Dialogal Discourse Markers: Kriol Ata and Spanish $S_{i}{ }^{15}$}

According to Schwenter $(1999,2002) s i$ is an adversative discourse marker, which is generally limited to colloquial conversation. ${ }^{16}$ It makes no truth-conditional contribution to its host proposition and must be used in a refutation of some aspect of preceding discourse, whether that aspect is propositional, presuppositional, inferential, metalinguistic, etc. In terms of syntactic position, si is required to be sentence initial. Further, si must appear in a dialogue rather than a monologue: i.e. it must be used to respond to a second speaker. Finally, Schwenter describes the refutation in question as exclusive, which means that the $s i$-marked content is incompatible with that which it refutes.

$\overline{{ }^{14} \text { For example, Comrie (1976: 111) }}$ defines markedness much more generally:

The intuition behind the notion of markedness in linguistics is that, where we have an opposition between two or more members [...], it is often the case that one member is felt to be more usual, more normal, less specific than the other (in markedness terminology it is unmarked, the others marked).

${ }^{15}$ Schwenter (1999) derives this form and meaning of $s i$ from the Spanish conditional protasis marker $s i$ 'if'. According to Schwenter, these different meanings (and others) should be understood as polysemous dimensions of the same form, positioned on a scale of relative distance from the conditional marker. See Schwenter (1999:

Chapters 4-5).

${ }^{16}$ Schwenter (1999: 126) uses the term "adversative" as opposed to "contrastive", as he argues that the former is a general cognitive concept, while "adversativity is a purely linguistic notion". This point is well taken, and I believe ata could just as easily be described in terms of adversativity rather than contrast; however, the account of ata given here is generally situated in a tradition which uses terms such as "contrast" and "contrastive discourse marker", so I retain those terms for consistency. 
Kriol ata appears to line up almost directly with Spanish si. The obvious difference thus far is that ata requires its contrast be made emphatically, and this does not seem to be the case with a si-refutation, which certainly can be emphatic but which needn't be. Further, I'm not certain it's the case that ata content must be completely incompatible with the contrasted discourse content. My hesitation hinges on the ata example given above in (1), in which the ata content and contrasted discourse content might not be completely exclusive. I will discuss this example and its implications in terms of exclusivity in more detail below. Before doing so, however, let's consider some of the sidata and how it compares to ata more generally.

Consider (24) [Schwenter (1999: 4.15)], in which $s i$ is used in a propositional refutation, with respect to who hung up the phone on whom:

[M recounting a telephone incident between Q and Q's boyfriend T]

M: $\quad$ y resulta que se cabreó y le colgó!

'and it turns out that she (Q) got mad and she hung up on him!'

G: $\quad$ Si le colgó él a ella.

'SI he hung up on her.'

M: $\quad$ Ah, le colgó él a ella? Pues ahora me entero.

'Ah, he hung up on her? Well now I find out.'

In (24), si contributes no truth conditional content to M's statement. As Schwenter demonstrates, $s i$ is optional in the refutational, declarative uses such as (24). Further, the content of G's refutation is incompatible with that of M's: either she hung up on him, or he hung up on her. Notice, though, that the $s i$-statement need not be understood as being an emphatic rejoinder to M's claim above.

Now consider a second example with $s i$, in which it signals a refutation with a conversational implicature in the preceding discourse. In (25), speaker A implicates that B likes only a particular flavor of Kool-Aid. Q then refutes this implicature with a $s i$-statement.

[B (age 6) looks strangely at a glass of purple Kool-Aid]

B: ¿Qué es eso?

'What is that?'

A: Es el que te gusta a ti.

'It's the one that you like.'

Q: $\quad$ Si a ella le gustan todos los sabores.

'SI she likes all of the flavors.'

Again, the presence of si does not make a truth conditional contribution to its host proposition. The si-content is also incompatible with the implicature A conveys, which is that purple is the only flavor B likes. Thus, Q's $s i$-statement is a refutation of A's conversational implicature, which it marks as incompatible with the $s i$-content. 
As I mentioned above, it is not clear that ata must make a clear exclusive refutation, where the ata-content is completely incompatible with the contrasted discourse content. Consider (1) again. The ata-statement seems to contrast with a conversational implicature generated by A's question: B takes A to imply that she was wrong to hit her sister.
A: Wai yu nak yu sista?
B: $\quad$ Ata da shee nak me fos!
A: Why did you hit your sister?
B: $\quad$ (But) it was she who hit me first!

My hesitation here, and it is a mild one, is that it might be too strong to say that B's atastatement is clearly incompatible with A's implicature. That is, B could actually believe it was wrong to hit her sister, as A implies, but at the same time offer the ata-statement as an explanation for her action. This is tricky for a couple of reasons. For instance, we can't really know the actual content of A's conversational implicature. B might have inferred a message that is completely incompatible with her ata-statement, and in this case, ata would line up exactly with Schwenter's depiction of $s i$ and exclusive refutation. On the other hand, B might have inferred a message from A that is logically compatible with B's ata statement, but with which B still desires to make an emphatic contrast. In this latter case, ata would differ from Schwenter's account of si. I don't have an answer for this possible difference between the two at the present; however, future research will certainly be undertaken to clarify this.

We have seen, then, that ata and $s i$ are quite close along many dimensions: much closer in fact than either of them is to any English counterpart. They do appear to differ in terms of emphaticness and possibly in terms of strength of refutation as well.

In the final section, I will suggest a possible origin for ata in the Kriol focus marker $d a$.

\section{Da: A Possible Source for Ata}

The origin of ata is an interesting question. Many words in Belizean Kriol are transparently derived from English words and so their origins are straightforward. With ata, however, a source - English or otherwise - is not easy to locate. In this final section, I suggest very briefly a likely source for ata in the Kriol focus marker $d a$.

Doing diachronic work on any creole is necessarily challenging, as they are almost always stigmatized languages with no writing system or written tradition. There are glimmerings of change here, though, with the development of alphabets in some creole languages, and some artists beginning to write poetry in fiction in creole. Most of this, however, is far too recent to provide the kind of record necessary to do diachronic work. As a result, what follows here is 
mostly speculative, based on an existing form in the language that has a broader function but which has a similar phonology.

The morpheme $d a$ is a general focusing element in Kriol, which can occur at the sentence level or internally, highlighting a predicate, embedded sentence, or other constituent. According to Escure (1993), focus marker $d a$ has likely been derived from demonstrative dat 'that'. She writes further of the focusing $d a$ that it is "in effect a functional equivalent of the English clefted construction" (235). And indeed, sentence-initial $d a$ is frequently rendered in it-cleft form when translated. Here are some samples from Decker (2005: p.98-99):

(26) Da Jan weh gwain da Jamayka.

'It is John who is going to Jamaica.'

(27) Da Jan weh shub di kyaat.

'It was John who pushed the cart'.

(28) Da wahn buk weh Jan gi mi.

'It was a book that John gave to me.'

It-clefts have been known to have focusing and contrastive properties since at least Jespersen (1949: 147f.), who describes clefts as:

A cleaving of a sentence by means of it is (often followed by a relative pronoun or connective) serves to single out one particular element of the sentence and very often, by directing attention to it and bringing it, as it were, into focus, to mark a contrast.

Since Jespersen's work, cleft sentences have been discussed at great lengths in the linguistics literature in terms of their semantic and pragmatic properties. ${ }^{17}$ The properties of focus and contrast are mostly a general consensus, though how these shake out in terms of constructional or compositional semantics and pragmatics is less agreed upon.

In any case, it seems not a far leap from focus marker $d a$, which creates cleft sentences, to the full contrastive marker ata. It seems likely that a sense of $d a$ could have undergone semantic narrowing, resulting in the discourse marker ata, which marks an emphatic contrast as opposed to the more broad focus of $d a$. If this was the case, then it would be unsurprising that the phonological form of $d a$ would have shifted as well with the change in meaning.

\footnotetext{
${ }^{17}$ I will not rehearse the cleft literature here. Readers are referred to Prince (1978), Hedberg (1990), Lambrecht (1994, 2001), Patten (2012), and the many references found in these works for detailed discussion of the syntax, semantics, pragmatics, and diachronic development of $i t$-clefts.
} 
This paper has provided a brief look at the discourse marker ata in Belizean Kriol. I have argued that ata is used to convey an emphatic contrast with the immediately preceding discourse and that this contrast is a conventional implicature of the type described in Grice (1975). It also frequently is used to convey negative emotion, which I argue is not semantically encoded in the word but that should instead be calculated in context via Gricean pragmatic reasoning as a conversational implicature. Finally, I sketched a brief diachronic origin for ata in the Kriol focus marker $d a$. This last part of the paper awaits a more comprehensive treatment in later work.

\section{References}

Akmajian, Adrian. 1984. Sentence types and the form-function fit. Natural Language \& Linguistic Theory 2: 1-23.

Bach, Kent. 1999. The Myth of Conventional Implicature. Linguistics \& Philosophy 22: 327366.

Biber, Douglas, et al. 1999. Longman Grammar of Spoken and Written English. Ninth Impression, 2011. Essex: Pearson.

Blakemore, Diane. 2002. Relevance and Linguistic Meaning: The Semantics and Pragmatics of Discourse Markers. Cambridge: Cambridge University Press.

Carston, Robyn. 2002. Thoughts and Utterances. The Pragmatics of Explicit Communication. Oxford: Blackwell.

Carston, Robyn. 2004. Relevance Theory and the Saying/Implicating Distinction. In Laurence Horn \& Gregory Ward, eds., The Handbook of Pragmatics, pp. 607-632. Malden, MA: Blackwell.

Comrie, Bernard. 1976. Aspect: An Introduction to the Study of Verbal Aspect and Related Problems. Cambridge: Cambridge University Press.

Decker, Ken. 2005. The Song of Kriol: A Grammar of the Kriol Language of Belize. Belize: The National Kriol Council, House of Culture. 2nd ed. 2009.

Escure, Genevieve. 1993. Focus, Topic Particles, and Discourse Markers in the Belizean Creole Continuum. In Donald Winford, ed., Focus and Grammatical Relations in Creole Languages, pp.233-249. Amsterdam: John Benjamins.

Escure, Genevieve. 1997. Creole and Dialect Continua. John Benjamins, Amsterdam.

Fillmore, Charles, et al. 1988. Regularity and Idiomaticity in Grammatical Constructions: The Case of 'Let Alone'. Language 64: 501-538.

Fraser, Bruce. 2006. On the Universality of Discourse Markers. In Karen Aijmer (ed.), Pragmatic Markers in Contrast, pp. 73-92. Amsterdam: Elsevier.

Frege, Gottlob. 1918. The Thought. In Michael Beaney, ed., The Frege Reader, pp. 325-345. Translated by Geach and Stoothoff. Oxford: Blackwell.

Greene, Laurie. 1999. A Grammar of Belizean Creole. New York: Peter Lang. 
Grice, Paul. 1975. Logic and Conversation. In Peter Cole and Jerry Morgan, eds., Syntax and Semantics. Vol. 3. Speech Acts, pp. 41-58. New York: Academic Press.

Grice, Paul. 1989. Studies in the Way of Words. Cambridge, MA: Harvard University Press.

Hall, Allison. 2004. The Meaning of But: A Procedural Reanalysis. University College London Working Papers in Linguistics.

Hedberg, Nancy. 1990. The Discourse Function of Cleft Sentences in English. Ph.D. dissertation, University of Minnesota.

Herrera, Yvette, et al., 2007. Kriol-Inglish Dikshineri/English-Kriol Dictionary. Fourth Printing, 2010. Belmopan, Belize: The National Kriol Council, House of Culture.

Horn, Laurence. 1984. Toward a New Taxonomy for Pragmatic Inference: Q-based and R-based Implicature. In Deborah Schiffrin, ed., Meaning, Form, and Use in Context: Linguistic Applications, pp. 11-42. Washington, DC: Georgetown University Press.

Horn, Laurence. 2004. Implicature. In Laurence Horn \& Gregory Ward, eds., The Handbook of Pragmatics, pp. 3-28. Malden, MA: Blackwell.

Horn, Laurence. 2013. I Love Me Some Datives: Expressive Meanings, Free Datives, and FImplicature. In: Daniel Gutzmann et al., eds., Expressives and Beyond: Explorations of Conventional Non-Truth-Conditional Meaning, pp. 143-189. Oxford: Oxford University Press.

Huang, Yan. 2007. Pragmatics. Oxford: Oxford University Press.

Huddleston, Rodney \& Geoffrey Pullum. 2003. The Cambridge Grammar of the English Language. Cambridge: Cambridge University Press.

Jespersen, Otto. 1949. A Modern English Grammar on Historical Principles. Part VII. Syntax. Copenhagen: Ejnar Munksgaard.

Karttunen, Laurie \& Stanley Peters. 1979. Conventional Implicature. In Choon-Kyu Oh \& David Dinneen, eds., Syntax and Semantics 11: Presupposition, pp. 1-56. New York: Academic Press.

Lambrecht, Knud. 1990. What, Me Worry? Mad Magazine Sentences Revisited. Berkeley Linguistics Society 16: 215-228.

Lambrecht, Knud. 1994. Information Structure and Sentence Form: Topic, Focus, and the Mental Representation of Discourse Referents. Cambridge: Cambridge University Press.

Lambrecht, Knud. 2001. A Framework for the Analysis of Cleft Constructions. Linguistics 39: 463-516.

Levinson, Stephen. 1983. Pragmatics. Cambridge: Cambridge University Press.

McCawley, James. 1978. Conversational Implicature and the Lexicon. In Peter Cole, ed., Syntax and Semantics 9: Pragmatics, pp. 245-258. New York: Academic Press.

Ochs, Eleanor. 1979. Planned and Unplanned Discourse. In Talmy Givon, ed., Syntax and Semantics, Vol. 12: Discourse and Syntax, pp. 51-80. New York: Academic Press.

Patten, Amanda. 2012. The English It-Cleft: A Constructional Account and a Diachronic Investigation. Berlin: Mouton.

Potts, Christopher. 2005. The Logic of Conventional Implicatures. Oxford: Oxford University 
Press.

Prince, Ellen. 1978. A Comparison of Wh-Clefts and It-Clefts in Discourse. Language 54: 883906.

Salmon, William. 2011. Conventional Implicature, Presupposition, and the Meaning of Must. Journal of Pragmatics 43: 3416-3430.

Salmon, William. 2014. The Contrastive Discourse Marker Ata in Belizean Kriol. Lingua: 143: 86-102.

Schwenter, Scott. 1999. Pragmatics of Conditional Marking. New York: Garland.

Schwenter, Scott. 2002. Discourse Markers and the PA/SN Distinction. Journal of Linguistics 38: 43-69.

Toosarvandani, M., to appear. Contrast and the Structure of Discourse. Semantics and Pragmatics.

Young, Colville. 1973. Belize Creole: A Study of the Creolized English Spoken in the City of Belize in its Cultural and Social Setting. Ph.D. dissertation, York University. 